\title{
Moving towards the sustainable city: the role of electric vehicles, renewable energy and energy efficiency
}

\author{
J. Prata ${ }^{1}$, E. Arsenio ${ }^{2}$ \& J. P. Pontes ${ }^{3}$ \\ ${ }^{1}$ BI FCT - Foundation for Science and Technology, Portugal \\ ${ }^{2}$ LNEC I.P. Department of Transport, Portugal \\ ${ }^{3}$ ISEG, Technical University of Lisbon, Portugal
}

\begin{abstract}
Integrated energy and urban mobility systems are key components for achieving cities' sustainability. Several urban metabolism approaches are emerging as leading tools for quantifying energy consumption and use patterns of resources in urban environments. Examples are the mass balance accounting (or energymaterials flux approach) using several quantification methods such as material flow analysis and life cycle assessment and Odum's emergy methods. In this research we adapt the extended metabolism model of a city developed by Newman (Sustainability and cities: extending the metabolism model 1999) and the material and energy flow accounting by Sheeri (UK material flow accounting 2002) to assess the future role of electric vehicles, renewable energy use for mobility needs and energy efficiency increases for households living in the city of Aveiro, a medium-sized city of 78,450 inhabitants in Portugal. The data used comprised an integrated set of energy, transport, socio-economic and solid waste production/treatment collected at the local and National level as part of the research project COST-TRENDS funded by the Portuguese Foundation for Science and Technology. The analysis of the potential energy mix (energy inputs from different sources) and households' mobility needs refers to the horizon 2010-2020. Several energy sources were considered: hydric, wind, solar (thermic and photovoltaic) and solid waste (incineration and biogas). Potential accessibility indicators were developed to better converge towards sustainable mobility objectives, measuring the potential for interaction and exchange of services and opportunities. Different household's profiles were established to represent consumers' behaviour. It was found that the above integrated energy
\end{abstract}


system could provide a total of 2.6 MWh/household/year, which represents on average around $26.0 \%$ of the actual total energy needs for households' daily mobility and 1.3 tonnes $\mathrm{CO}_{2}$ /household/year avoided. On the other hand, the replacement of a conventional internal combustion engine by battery electric vehicles could allow an energy reduction of 7.4 MWh/household/year until 2020 and a reduction of 2.5 tonnes $\mathrm{CO}_{2} /$ household/year.

Keywords: energy efficiency, $\mathrm{CO}_{2}$ emissions, cities' sustainability, emerging technologies (electric vehicles), transport policy and planning.

\section{Introduction}

Environmental and energy related issues, along with economic and technology led factors are crucial for cities to converge towards sustainability. Without a technological shift, the EU will fail on its 2050 ambitions to decarbonise the electricity and transport sector [1, 2]. The EC Transport White draws 10 goals for a competitive and resource efficient transport systems, aiming to achieve a $60 \%$ GHG emission reduction. Cities have an important role to accommodate for European policies because these represent centres of high energy consumption, waste creation along with $\mathrm{CO}_{2}$ free emissions. As such, conventionally-fuelled cars are envisaged to be reduced by half until 2030 and fully replaced by Battery Electric Vehicles (BEVs) until 2050. As part of the research project COSTTRENDS funded by the Portuguese Foundation for Science and Technology, this paper adapts the extended metabolism model of a city developed by Newman (1999) and the material and energy flow accounting by Sheeri (2002) to assess the future role of electric vehicles (BEVs and electric bicycles) and renewable energy if these are used to fulfill citizens' mobility needs for daily functional trips. Accessibility indicators were included in this framework as well.

\section{Building an urban metabolism methodological approach: literature review}

\subsection{Background}

The sustainable city concept, based on the idea of a self-sufficient system, is in practice very difficult to achieve [3,4]. However, if the sustainable city principles are followed to target efficiency, cities will get closer to sustainable consumption patterns. The goal of urban sustainability can be defined as the "reduction in the use of natural resources and production of wastes of a cityregion while simultaneously improving its livability, in terms of social amenity and health, so that it can better fit within the capacities of the local, regional and global ecosystems" [5]. Following Shen et al. [6], urban sustainability indicators refer to four important dimensions: (i) environmental, such as freshwater, wastewater, air quality, noise pollution, sustainable land use, waste generation and management, greener transportation systems; (ii) economic, such as consumption and production patterns, economic development, finance (iii) social, such as energy and water access, education, health, safety, 
transportation, adequate housing, shelter, culture, green places, social integration and support disadvantageous groups, and (iv) governance, such as efficient governance, participation and civic engagement, sustainable management of the authorities and businesses. Following McDonald and Patterson [7], Patrick Geddes (1854-1932), who was a biologist with an innovative thinking about urban planning, concerned itself about non-accounting of flow materials in urban areas. Abel Wolman developed the concept of urban metabolism with a model accounting for the material inputs and outputs in an urban system [8]. Urban metabolism can be represented as the global sum of all processes that occur in cities, which can be technical and socio-economic changes and metabolic balances related to growth promotion, energy production and waste elimination $[9,10]$.

\subsection{Urban Metabolism approaches: Odum's emergy and the energy-materials flux approaches}

Howard T. Odum (1924-2002) developed the concept of emergy (emJ), which represents energy quality. Several energy forms have different qualities. Solar energy is considered by Odum as very important since it represents the basis of all energy sources. The quality of energy cannot be expressed by energy units, as cal, btus, kWh, J, etc. [11] because the energy quality must be measured by energy used in the transformation form to another form [12]. To society the value of energy is represent by net energy, which is related to its quality and monetary value [11]. Emergy allows the quantification of energy, materials and monetary flows in the urban metabolism, where the cities are compared to organisms, with particular metabolic processes [13]. Although there exists several studies using Odum's emergy methods for the case of ecological systems, few applications have been made to the case of urban planning due to its complexity $[9,14]$.

The mass balance accounting (or energy-materials flux approach) is represented by several quantification methods such as material flow analysis (MFA) and life cycle assessment, allowing us to quantify both energy and material consumption to characterize the urban metabolism [14]. The MFA was first applied for the case of local industrial processes (industrial metabolism) [15] and in the 90s it was extended to the national level such as in Austria and Japan [16]. To our knowledge the MFA was formerly applied in Portugal by Niza et al. [17] to study the urban metabolism for the city of Lisbon. The urban system can be considered as an open steady system because it is possible to account for (i) the energy input that is converted to an output of pollutants (if the energy source is entirely renewable there are no emissions); (ii) the material inputs that are converted into waste outputs and other effluents; (iii) the imports and exports, stocks, that represent externalities associated to the socio-economic metabolism [14, 15, 18]. As such, the reintegration of output flows into inputs than re-enter in the urban system will increase city's efficiency. The Extended Metabolism Model (EMM) of a city developed by Newman [5] used in this research, was based on the experience of the Human Settlements Panels in the Australia State of the Environment Reporting process, which have include 
the dynamics (transportation, economic and cultural priorities) and livability in these settlements (health, employment, income, education, housing, leisure activities, accessibility, urban design quality and community). In addition, we have used the material and energy flow accounting by Sheeri (2002) for the case study analysis. The EMM is similar to the MFA and it can be applied to: (i) industry; (ii) household; (iii) comparison between different cities and (iv) firms [19]. On the other hand, the MFA approach comprises economic data providing an economic interpretation about the region [18].

\subsection{Accessibility indicators}

"Sustainable mobility requires that the mobility benefit (accessibility) does not come at the cost of reducing capacities of essential systems to also provide welfare-increasing opportunities" [20]. Although accessibility can have several meanings it can be understood as: "the potential of opportunities for interaction" [21]; "the ease with which any land-use activity can be reached from a location using a particular transport system" [22]; "the freedom of individuals to decide whether or not to participate in different activities" [23]; "the benefits provided by a transportation/land-use system" [24]; "the extent to which the land usetransport system enables (groups of) individuals or goods to reach activities or destinations by means of a (combination of) transport mode(s)" [25]; "a measure of the ease of an individual to pursue an activity of a desired type, at a desired location, by a desired mode, and at a desired time" [26]; "the amount and diversity of places that can be reached within a given travel time and/or cost" [27]. In this research we use the potential accessibility indicator concept. The analysis considered the potential accessibility of one parish (sub-unit the city system) in relation to the other parishes in the city-region, given the weighted potential of attraction/generation of each centre (parish). The accessibility indicator $\left(A_{p}\right)$, can be represented through the following equation:

$$
A_{p}=\sum_{j=1}^{N} \frac{P_{j}}{t(p j)}
$$

where: $t(p j)$ is the time travel (in minutes) between different parishes $(p) ; N$ is the number of parishes; $P_{j}$ is the attraction/generation potential of each parish, measured the total employment per activity sector.

\section{The case study at the city of Aveiro}

\subsection{Methodology details}

As mentioned in section 2.2, this research adopted the MFA by Sheeri (2002) and the EMM approach by Newman (1999) to the city of Aveiro, a mediumsized city in Portugal. The methodology comprised the following steps:

(a) Application of the MFA to analyse energy and materials flows (inputs and outputs). The energy sources (inputs) were identified for mobility needs 
using electricity, natural gas and fossil fuels. Inputs for basic human needs were water, food, waste and pollutants $\left(\mathrm{CO}_{2}\right)$.

(b) Analysis of the potential energy mix available for future household mobility needs until de 2020 horizon. It was analysed the energy efficiency that could be achieved from the integration of renewable energy and electric vehicles for daily functional trips. Energy inputs per household considered the use of one microturbine (97 kW) [28], use of wind energy turbine (5kW - viable for each 10 households), solar energy (two PV $(0.3 \mathrm{~kW})$ and thermal panels per household [29] and solid waste (incineration and burning of biogas [30]).

(c) Characterization of typical household profiles regarding key patterns of consumer behaviour (mobility centred). This had considered the collection of several types of data, such as transport and mobility, energy and socioeconomic variables (household size, age structure, etc.). The reference situation data refers to 2011.

(d) Analysis of households' accessibility for the reference situation (2011) and for the long-term scenario (2020). Accessibility indicators were computed for the private car (most used transport mode). For exploring more sustainable mobility forms in the future, the option of electric vehicles was considered (electric bikes for short distance trips).

During the analysis, we have developed an economic interpretation of the results using the economic export base theory. For this purpose, the city economy was split into three economic sectors (I - Primary sector, II Secondary, II - Tertiary). The energy intensity of each economic sector was computed in relation to the amount of output.

\subsection{Characterization of the city of Aveiro: socio-economic and mobility indicators}

Aveiro is a medium-sized city of 78,450 inhabitants located in the sub-region of Baixo Vouga, of the Centro Region in Portugal. Considering the most recent available statistical data (INE, 2012), 31142 households are distributed by 14 parishes. Their household structure is as follows: 23.4\% (1 person); 32.7\% (2

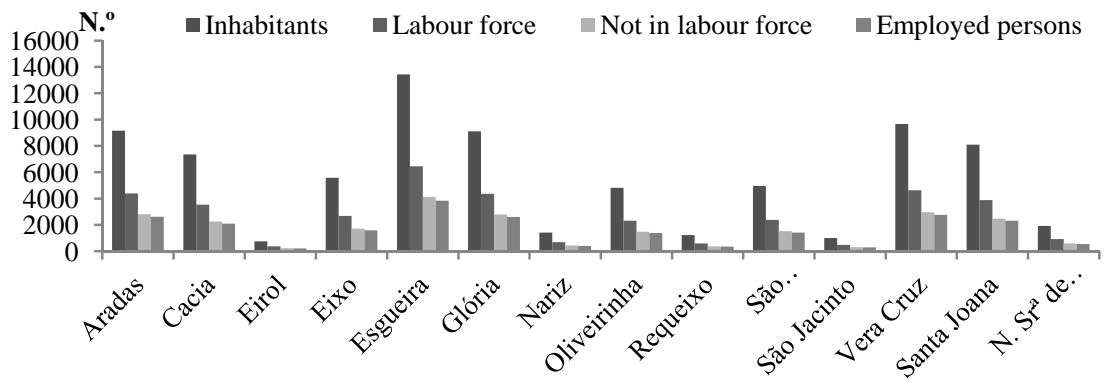

Figure 1: $\quad$ Population and employment indicators for the city of Aveiro [32]. 
persons); 22.5\% (3 persons); 15.9\% (4 persons); and 5.5\% (5 or more persons) [31,32]. Figure 1 presents a synthesis of the resident population and employment indicators. Esgueira is the parish with the highest population.

The daily movements of $61.6 \%$ of the Portuguese population are made by car (17.9\% of people use it as passengers whereas $43.7 \%$ do it as drivers [32]). The same mobility patterns are replicated for the city of Aveiro. It was found that most students under 15 years of age who travel to school use their parents' car as a passenger in their daily trips. In line with this indicator, $17.9 \%$ of drivers leave children at school as part of their commuting trips to work. These drivers are members of households with 3 or more people, which have at least 1 person aged below 15 years.

Table 1 shows the employment for each economic sector and the respective gross value added (GVA), including the total values for the sub-region of Baixo Vouga. It shall be noted that a significant percentage of the labour force (35.6\%) reside in other municipalities (external to the city of Aveiro boundaries).

Table 1: Total employment for each economic sector and GVA for the city of Aveiro and for the sub-region of Baixo Vouga [31, 32].

\begin{tabular}{|l|c|c|c|c|}
\hline $\begin{array}{c}\text { Economic } \\
\text { sector }\end{array}$ & $\begin{array}{c}\text { Total } \\
\text { employment } \\
\text { Aveiro }\end{array}$ & $\begin{array}{c}\text { Aveiro } \\
\text { GVA (M€) }\end{array}$ & $\begin{array}{c}\text { Total } \\
\text { employment } \\
\text { in the sub- } \\
\text { region }\end{array}$ & $\begin{array}{c}\text { GVA in the } \\
\text { sub-region } \\
\text { (M€) }\end{array}$ \\
\hline Primary & 383 & 1.389 & 4398 & 56.375 \\
\hline Secondary & 8442 & 345.328 & 51608 & 1482.721 \\
\hline Tertiary & 26966 & 420.691 & 112828 & 1299.806 \\
\hline Total & 35791 & 767.408 & 168834 & 2838.902 \\
\hline
\end{tabular}

As mentioned in section 3.1, this research adapted the theory of the economic export base to determine which economic sector in the city was the main exporter. The economic indicator, $Q_{K}$, which is based on the relation between the GVA and the total employment for each economic sector is described below:

$$
Q_{K}=\frac{G V A_{K} / G V A}{E_{K} / E}
$$

where: $G V A_{K}$ is the gross value added for the city of Aveiro for the economic sector $k$; $G V A$ is the total gross value added for the city of Aveiro; $E_{K}$ is the total employment in the economic sector $k$ in the sub-region, and $E$ is the total employment in the sub-region. If $Q_{K}$ is greater than one, the economic sector $k$ is the exporter (the export "motor" for the urban economy and where efficiency targets might deserve more allocation of resources).

Using the above formulation (equation 2) and the data in Table 1, it was found that the secondary sector (industry) was the exporter $\left(Q_{K}=1.47\right)$. This is line with industrial location patterns in the sub-region, which concentrates 
metallurgic, automotive components such mechanical and electronic, amongst others.

Considering the energy resources consumption (kWh) of each economic sector $[33,34]$ and the respective GVA $(€)$, the energy intensity relative to GVA (kWh/€) is as follows: 0,46 kWh/€ (primary sector); 0,82 kWh/€ (secondary sector) and $0,21 \mathrm{kWh} / €$ (tertiary sector). The energy resources data (inputs) included natural gas and electricity only. It shall be noted that disaggregated data on fuel or coal did not exist. As such, the tertiary sector is the one that needs lower energy inputs to produce the same amount of output, ceteris paribus. Since the secondary sector is the exporter, we must conclude that this economic sector is the one that deserves more attention for increasing energy efficiency in relation to GVA.

\subsection{Material and energy flux analysis}

The analysis used an integrated data collection of energy consumption, transport, solid-waste production and treatment, water and food consumption data for the city of Aveiro [31-35]. The material and energy flux analysis for the city of Aveiro considered a typical household which was found to have a size of 2.5 persons and 1.25 motorized vehicles [32]. This research used the sustainability potential concept, which is associated to the lowest possible energy and resources' consumption. It is associated with producing the minimum waste, water effluents and air pollutants, treating and managing these outputs in the most efficient way, valuing these outputs whenever possible, allow their reintegration in the system (as energy or materials) and maximize the production of energy using renewable resources whenever this option represents economic advantages. Table 2 shows the results of the MFA for city of Aveiro for the reference year 2011, having as key output the equivalent $\mathrm{CO}_{2}$ emissions

Table 2: $\quad$ Material and energy flux analysis for Aveiro.

\begin{tabular}{|c|c|c|c|}
\hline Description & $\begin{array}{c}\text { Quantity } \\
\left.\text { (kg.year }^{-1} \text { or kWh.year }{ }^{-1}\right)\end{array}$ & End-use & $\begin{array}{c}\text { Emissions } \\
\left(\mathrm{kg} \mathrm{CO}_{2 \text { eq. }} \text { year }^{-1}\right)\end{array}$ \\
\hline Food (M) & 2349 & \multirow{4}{*}{ Stock in. } & NA \\
\hline Electricity (E) & 3594 & & 1581 \\
\hline Natural Gas (E) & 2363 & & 738 \\
\hline Fuel Transportation (E) & 9929 & & 3972 \\
\hline \multirow{2}{*}{ Water $(\mathrm{M})^{*}$} & 241423 & Supply in. & NA \\
\hline & 241423 & Treatment. & NA \\
\hline Waste $(\mathrm{M})$ & 1021 & Landfill out. & 182 \\
\hline Total & \multicolumn{2}{|l|}{$(E)=15886(M)=3370$} & $\mathrm{GE}=6472$ \\
\hline
\end{tabular}

NA=Not available (negligible); in.= input; out.= output (treatment considered); $(\mathrm{M})=$ material flux; $(E)=$ material flux; *after water treatment, it was assumed that this will be available for consumption again; thus it will not be considered in the sum; GE=Global Emissions.

In order to understand the sustainability potential of the city of Aveiro, having the 2020 horizon, each household was assumed to choose different renewable 
energy (RE) options for electricity generation, improving energy efficiency and for adopting emerging vehicles technologies - electric vehicles. The material inputs (food, water and waste) were assumed the same for all the city households in the analysis. However, the output related with $\mathrm{CO}_{2}$ emissions changed according to each type of the greener technologies to be introduced. One of these greener technologies was the introduction of BEV's, a technological measure in line with the European transport policy [28, 31-37]. Table 3 presents the results regarding the potential MFA for Aveiro and the output as equivalent $\mathrm{CO}_{2}$ emissions for 2020, having as reference year 2011.

Table 3: $\quad$ Material and energy flux analysis for Aveiro for 2020.

\begin{tabular}{|c|c|c|c|c|}
\hline \multicolumn{2}{|c|}{ Description } & $\begin{array}{l}\text { Quantity } \\
\text { (kg.ano-1 or } \\
\text { kWh.ano-1) }\end{array}$ & End-use & $\begin{array}{c}\text { Emissions } \\
\left(\mathrm{kg} \mathrm{CO}_{2}\right. \\
\text { eq.ano-1) }\end{array}$ \\
\hline \multirow{5}{*}{$\begin{array}{l}\text { Electricity } \\
\text { generated } \\
\text { by RE (E) }\end{array}$} & Water supply & 23 & \multirow{9}{*}{ Stock in. } & -10 \\
\hline & Solar PV & 1046 & & -460 \\
\hline & Wind turbine & 204 & & -90 \\
\hline & Waste incineration & 428 & & -547 \\
\hline & Biogas & 312 & & 57 \\
\hline \multicolumn{2}{|c|}{ Electricity needs to supply (E) } & 1582 & & 696 \\
\hline \multicolumn{2}{|c|}{ Electricity needs for BEV (E) } & 2561 & & $(* *)-2544$ \\
\hline \multicolumn{2}{|c|}{ Natural Gas (E) } & 1796 & & 561 \\
\hline \multicolumn{2}{|c|}{ Solar thermal (E) } & 567 & & -177 \\
\hline \multicolumn{2}{|c|}{ Waste $(\mathrm{M})$} & 128 & Landfill out. & NA \\
\hline \multicolumn{2}{|c|}{ Waste Collection $(\mathrm{M}) *$} & 215 & Treatment out. & NA \\
\hline & Total & $(E)=8519$ & \multicolumn{2}{|c|}{$\mathrm{GE}=2741 \mathrm{EA}=3828$} \\
\hline
\end{tabular}

EA= Emissions Avoided; ** Emission of $1428 \mathrm{~kg} \mathrm{CO}_{2 \text { eq }}$.ano ${ }^{-1}$ associated to electricity generation.

From Table 3, it is found that the integration of renewable energy will represent a share of $56 \%$ in the potential electricity production in 2020 . Battery electric vehicle (BEV) would promote $74.2 \%$ of energy efficiency in the mobility daily needs (functional trips). These BEVs would be responsible for $64.0 \%$ reduction of $\mathrm{CO}_{2}$ emissions related to mobility. Considering the integrated energy system (mobility and energy household needs using renewable energy sources), it would be $46.4 \%$ more efficient and $61.8 \%$ greener than for the reference year used in the analysis. Table 4 shows the energy intensity of different household profiles for the city of Aveiro for 2011 and 2020. An integrated socio-economic data and the previous household consumptions for the city of Aveiro was used to determine the respectively energy intensity. It was assumed that each household contained at least one active member in the labour force. The household income data was based on the data provided by the CCDR-Centro [31].

From Table 4, it can be found that the integration of renewable energy and BEVs would promote a decrease of around 50\% in energy intensity for each household profile. 
Table 4: $\quad$ Energy intensity (kWh/€) for different household profiles.

\begin{tabular}{|c|c|c|c|c|}
\hline \multirow{2}{*}{$\begin{array}{c}\text { Household size } \\
\text { (\% of the city } \\
\text { population) }\end{array}$} & \multicolumn{4}{|c|}{ Energy Intensity (kWh/€) } \\
\cline { 2 - 5 } & 2011 (n. $^{\circ}$ employees) & 2020 (n. $^{\circ}$ employees) \\
\hline 1 person (23.4\%) & 1 & 2 & 1 & 2 \\
\hline 2 persons (32.7\%) & 6.0 & - & 3.0 & - \\
\hline 3 persons (22.5\%)* & 12.1 & 6.0 & 5.9 & 3.0 \\
\hline 4 persons (15.9\%)* & 18.1 & 9.1 & 8.9 & 4.4 \\
\hline
\end{tabular}

-It is not possible have 2 employees if the size of family is one person; *If the size of family is constituted by 3 or 4 persons it was assumed 1 or 2 persons aged under 15, since it represents $39.4 \%$ and $35.2 \%$ of population that family size; ${ }^{* *}$ For households of a size higher than 4 persons, the energy intensity wasn't computed and represents $5.5 \%$ of population.

\subsection{Accessibility measurement}

Using the formulation described in section 2.3, we have computed accessibility indicators for the reference year 2011 and the target scenario in 2020. To determine the travel time by car (most used transport mode for functional trips in 2011) between parishes (origin-destination) it was used the Google Maps (it shall be noted that highways were not considered due to the effect of road tolls). The attraction/generation of each parish was measured through its economic activity by sector. Cacia is the parish of Aveiro where most of the industry is located, representing around $80 \%$ of the secondary sector. Glória is the parish of Aveiro where around $75 \%$ of tertiary sector is located. The primary sector can be considered dispersed over the region, except for the cases of the parishes of Glória, São Bernardo, Vera Cruz and Santa Joana where this sector activity is not significantly represented. Figure 2 shows the accessibility measures for each parish, considering all economic sectors. Figure 3a) shows the accessibility for 2011, where mobility patterns are driven by conventional vehicles. Figure 3b) shows the accessibility potential for 2020, assuming an extreme scenario where electric bicycles (EB) would be used for short distance trips as the main transport mode in the city.

The travel time assumed for the EB (maximum speed of $25 \mathrm{~km} . \mathrm{h}^{-1}$ ) is assumed half of the one for conventional vehicles [38]. It shall be noted that all conventional vehicles were assumed to be replaced by EBs which represent an extreme scenario for our analysis of the potential accessibility. However, this replacement would allow $98.1 \%$ of energy reduction and $3893 \mathrm{~kg} \mathrm{CO}_{2 \text { eq }}$ per year, having as reference the year 2011.

Figure 3a) represents the actual accessibility for workers of each economic sector (workers that drive their children to school as part of their daily functional trips), for each parish. For the 2020 scenario, it was assumed that $50 \%$ of the students aged less than 15 years will use electric bikes for their daily trips to school, thus avoiding parents to divert their home to work trips. Figure 3b) represents the potential accessibility that could be achieved in this case. Accessibility units were achieved through multiplying the population in each economic sector/parish with the attraction/generation indicator related to this 

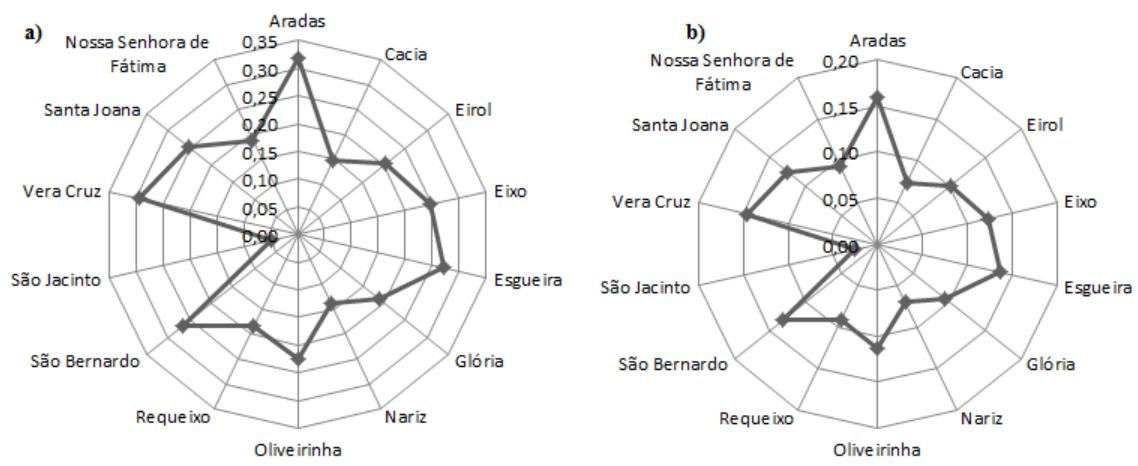

Figure 2: $\quad$ Accessibility for each parish in 2011, b) Potential accessibility for each parish in 2020.
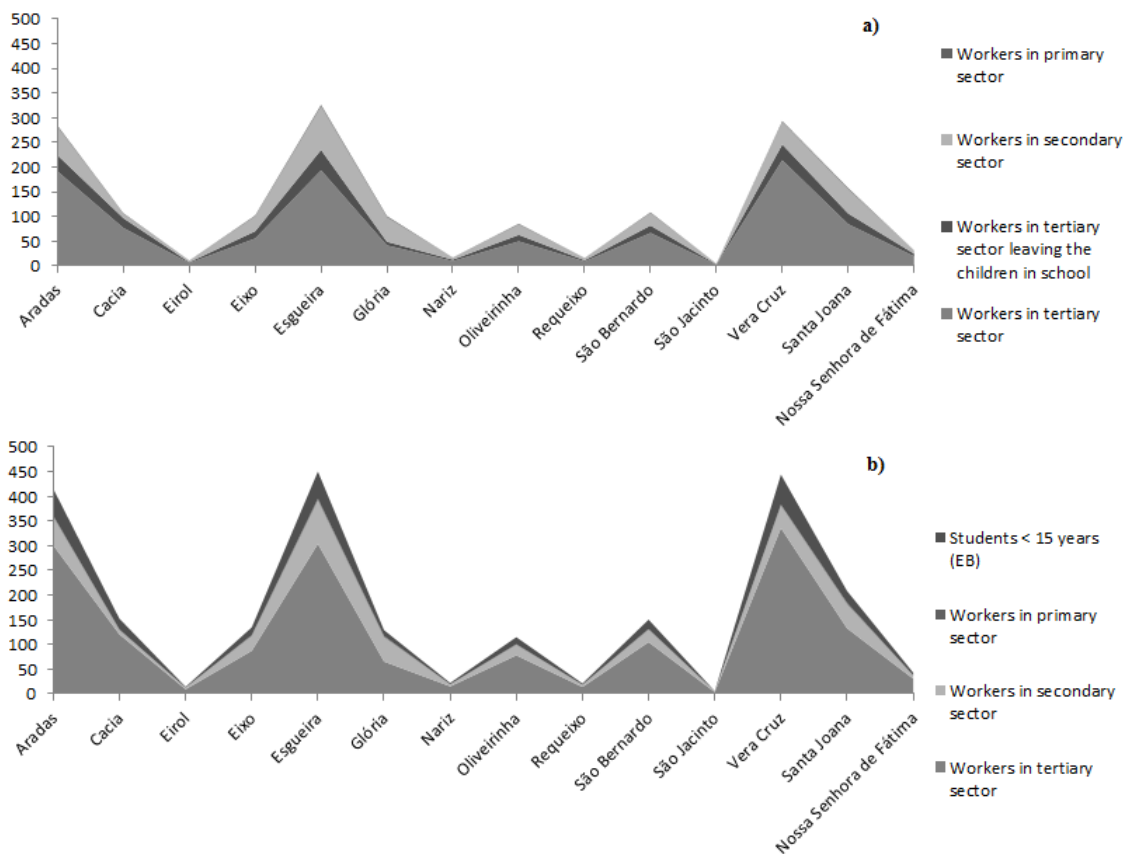

Figure 3: a) Short distance car based accessibility in 2011; b) potential accessibility due to a modal shift to electric bikes in 2020 .

land use category. For example, this would allow an increase of workers' accessibility of $57 \%$ for the tertiary sector. Considering that this potential might be underestimated since an average travel time reduction of 15 minutes per 
modal shift was considered, this is a promising result in favour of emerging vehicle technologies.

\section{Conclusions}

The integrated energy system of renewable energy sources could provide a total of $2.6 \mathrm{MWh} /$ household/year. This value represents $26.0 \%$ of the actual households' needs for daily functional trips and it would provide $100.0 \%$ of the 2020's energy mobility needs, avoiding around 1.3 tonnes $\mathrm{CO}_{2} /$ household/year.

The integrated energy and mobility system of renewable energy and electric vehicles would make the urban system $46.4 \%$ more energy efficient and $61.8 \%$ greener (reduction of $\mathrm{CO}_{2}$ emissions) than for the reference year used in the analysis. The replacement of conventional internal combustion engine by BEVs will allow an energy reduction of 7.4 MWh/household/year until 2020 and a reduction of 2.5 tonnes $\mathrm{CO}_{2}$ /household/year. On the other hand, BEVs would increase $74.2 \%$ of energy efficiency in the daily functional trips (reduction of $64 \%$ of $\mathrm{CO}_{2}$ emissions).

The full replacement in 2020 of all conventional vehicles by electric bikes (extreme scenario used in the analysis) is associated with an expected total reduction of $3893 \mathrm{~kg} \mathrm{CO}_{2 \text { eq }}$ per year, in comparison to 2011, could be achieved. For 2020, the use of electric bikes by $50 \%$ of students aged less than 15 years would allow to increase their parents/workers' accessibility around 57\%.

The city of Aveiro has still a significant potential to use existing renewable energy sources to generate electricity and to integrate electric vehicles, leading to a more efficient urban system. On the other hand, the analysis conducted shows that the objective of pursuing successfully the aims of energy efficiency and emission reductions $\left(\mathrm{CO}_{2}\right)$ will depend on the future actions of all households.

\section{Acknowledgements}

The authors would like to express their thanks to the Portuguese Foundation for Science and Technology (FCT) for funding this research through the R\&D COST-TREND project grant PTDC/EGE-ECO/115815/2009: COSTs of transport TRENDs in Portugal: the role of environmental externalities and industrial location.

\section{References}

[1] EC, Energy 2020 - a strategy for competitive, sustainable and secure energy, Brussels, 2010.

[2] EC, White paper - Roadmap to a Single European Transport Area Towards a competitive and resource efficient transport system, Brussels, 2011.

[3] Rees, W.; Wackernagel, M. - Urban Ecological Footprints: why cities cannot be sustainable - and why they are a key to sustainability. 1996. 
[4] Roy, M. - Planning for sustainable urbanisation in fast growing cities: Mitigation and adaptation issues addressed in Dhaka, Bangladesh. - HI, 2009.

[5] Newman, P.W.G. - Sustainability and cities: extending the metabolism model. , Landscape and Urban Planning, 1999.

[6] Shen, L.Y., et al. - The application of urban sustainability indicators - A comparison between various practices. Habitat International, 2011.

[7] McDonald, G. W.; Patterson, M. G. - Bridging the divide in urban sustainability: from human exemptionalism to the new ecological paradigm. Urban Ecosyst, 10, 2007.

[8] Wolman, A. - The metabolism of cities. Scientific American, 213, 1965.

[9] Kennedy, C., et al. - The changing metabolism of cities. Wiley, JIE, 2007.

[10] Gonzalez, A., et al. - A decision-support system for sustainable urban metabolism in Europe. , Environment Impact Assessment Review, 2012.

[11] Alberti, M. - Measuring urban sustainability. EIAR, 1996.

[12] Odum, H.T. - Energy, ecology and economics. RSAS. AMBIO 2 (6), 1973.

[13] Zhang, Y., et al. - Evaluation of urban metabolism based on emergy synthesis: a case study for Beijing (China), Ecological Modeling, 2012.

[14] Pincelt, S., et al. - An expanded urban metabolism method: toward a system approach for assessing urban energy processes and causes. LUP, 2012.

[15] Ayres, R.U. - Industrial ecology: a coming-of-age story. Resources for the Future 130, 1989.

[16] Hinterberger, F., et al. - Material Flow Accounting and Analysis (MFA) A Valuable Tool for Analyses of Society-Nature Interrelationships. Entry prepared for the Internet Encyclopedia of Ecological Economics, 2003.

[17] Niza, S., et al. - Urban metabolism: methodological advances in urban material flow accounting based on the Lisbon case study, JIE, 2009.

[18] Sheerin, C. UK material flow accounting. Economic Trends. London, 2002.

[19] Zonneveld, W. - Conceptvorming in de ruimtelijke planning: Encyclopedie van planconcepten (Concept formation in spatial planning: Encyclopedia of planning concepts). University of Amsterdam, Amsterdam, 1991.

[20] Zegras, P.C. - Sustainable Urban Mobility: Exploring the role at the Built Environmental, PhD thesis in Urban and Regional Planning, MIT, 2005.

[21] Hansen, W.G. - How accessibility shapes land use. JAIP, 1959.

[22] Dalvi, M.Q.; Martin, K.M. - The measurement of accessibility: some preliminary results. Transportation 5, 1976.

[23] Burns, L.D. - Transportation, Temporal and Spatial Components of Accessibility. Lexington Books, Lexington, Toronto, 1979.

[24] Ben-Akiva, M.; Lerman, S.R - Disaggregate travel and mobility choice models and measures of accessibility. In: Hensher, D.A., Stopher, P.R., (Eds), Behavioural Travel Modelling, Croom Helm, Andover, Hants, 1979.

[25] Geurs, K.T.; Wee B. van - Accessibility measures: a literature review. Accessibility evaluation of land-use and Transport Strategies: review and research directions. , Journal of Transport Geography 12, 2004. 
[26] Bhat, C., et al. - Development of an urban accessibility index: Literature review. Research project conducted for the Texas department of transportation. University of Texas, Austin, TX: Center for Transportation Research, 2000.

[27] Bertolini, L. et al. - Sustainable accessibility: A conceptual framework to integrate transport and land use plan-making. Two test-applications in the Netherlands and a reflection on the way forward. Transport Policy, 2005.

[28] Prata, J.; Andrade-Campos, A. - Development of a numerical tool for energy production in water supply systems. First ECCOMAS YIC, 49. Aveiro, 2012.

[29] Prata, J.; Lamas, T. - Integration of Renewable Energies in a pleasure boat in the Ria de Aveiro - EcoSunBoat, ESTGV, Viseu, 2009.

[30] Tchobanouglous, G., et al. - Integrated Solid Waste Management. Engineering Principles and Management Issues, McGraw Hill Book Co., 1993.

[31] CCDR-C, http://datacentro.ccdrc.pt/

[32] INE, www.ine.pt/

[33] National Education Diabetes Program, Fat and Calorie Counter.

[34] APA, Resíduos Urbanos em 2010, 2011.

[35] Prata, J.; Arsenio, E.; Pontes, J.P. - Future trends on the costs and benefits of electric, hybrid and conventional vehicles in Europe. $13^{\text {th }}$ WCTR. Rio, 2013.

[36] DGEG, http://www.dgeg.pt/

[37] PORDATA,_http://www.pordata.pt/

[38] ORBITA, http://www.orbita-bicicletas.pt 